\title{
Acknowledging and learning from smaller hospitals
}

The theme of this issue of the Future Healthcare Journal $(F H J)$ is 'small and rural hospitals'. As someone who works for Imperial College Healthcare NHS Trust, one of the largest providers in the UK, but also for NHS Orkney, one of the smallest, I feel a deep affinity with this subject. I am tremendously grateful to Dr Louella Vaughan for commissioning and collating the themed articles. Her own clinical and academic experience, her work with the Nuffield Trust and her authoritative publications in this area make her ideal to provide us with a balanced and challenging compendium of articles. To me, one of the most important messages is that the issues faced by smaller hospitals are in fact shared by our largest trusts - creating, training and valuing a sustainable workforce, maintaining patient-centred care within a community and a scepticism about the value of major organisational change. If you work in a small hospital, I am sure you will enjoy and feel a synergy with these articles. If you work in a large hospital or trust, I recommend you read and reflect on the pieces which you will discover to be surprisingly relevant.

This issue also contains the usual broad mix of other papers on organisational change and quality improvement. I particularly like the fact we have two papers looking at modelling the impact of change, and three reviewing and evaluating changes undertaken. I would hope in the future we could have paired articles modelling a change, linked to a post-implementation evaluation.

Daniel Chalk shows through a modelling process that extending the hours of an ambulatory care unit is more effective than extending the bed base. ${ }^{1}$ Dipankar Dutta et al model service expansion for mechanical thrombectomy for stroke. ${ }^{2}$ If this is to be rolled out, the resource implications are huge and their paper should be required reading for all.

The papers by Mark Sweeney et al and Chun Shing Kwok et al look at developing improved services for acute cardiac disease., Both papers show that the resource investment to facilitate patients being seen promptly in the right place by the right people can be clinically and cost effective. I admire greatly those able to work beyond the 'noise' in our overwhelmed services to innovate and improve and we will continue to champion service improvement by publishing the best examples. Submissions to the $\mathrm{FHJ}$ have been increasing and I am grateful to our associate editors, reviewers and editorial staff for their essential help in managing the expanding workload.

We have a new year, a new government and an opportunity to look to the future - we need an inter-party or non-party political conversation to move the healthcare agenda forwards. Effective future healthcare for our population will surely require a differently skilled and knowledged workforce, an embracing of digital technology in all its forms, and a paradigm shift to prevention and reducing inequality rather than treating end-stage disease. We intend to tackle all of these themes in forthcoming issues of the $\mathrm{FHJ}$.

Meanwhile, there is much we can all learn from the experiences of smaller hospitals and the communities they serve. I hope you enjoy this issue of the $\mathrm{FHJ}$.

Dr Kevin Fox Editor-in-chief (interim)

\section{References}

1 Chalk D. Using computer simulation to model the expansion needs of the ambulatory emergency care unit at Derriford Hospital. FHJ 2020;7:60-4.

2 Dutta D, Parry F, Obaid M, Ramadurai G. Mechanical thrombectomy in stroke - planning for service expansion using discrete event simulation. FHJ 2020;7:65-71.

3 Sweeney M, Bleeze G, Storey S et al. The impact of an acute chest pain pathway on the investigation and management of cardiac chest pain. FHJ 2020;7:53-9.

4 Shing Kwok C, Naneishvili T, Curry S. Description and development of a nurse-led cardiac assessment team. FHJ 2020;7:78-83.

$\begin{array}{lll}\text { Members of the editorial board } & & \\ \text { Debra Armstrong } & \text { Miriam Fine-Goulden } & \text { Louella Vaughan } \\ \text { Suzie Bailey } & \text { Graham Foulkes } & \text { Emma Vaux } \\ \text { Rodger Charlton } & \text { Kevin Fox } & \text { Sheena Visram } \\ \text { Mohsin Choudry } & \text { Neil Howie } & \text { Katharine Warburton } \\ \text { John Dean } & \text { Joanna Szram } & \text { Stephen Webb } \\ \text { Julia Ellis } & \text { Mark Temple } & \end{array}$

